\title{
Associations between smoking, components of metabolic syndrome and lipoprotein particle size
}

\author{
Sandra N Slagter ${ }^{1 \dagger}$, Jana V van Vliet-Ostaptchouk ${ }^{1 \dagger}$, Judith M Vonk ${ }^{2}$, H Marike Boezen², Robin PF Dullaart ${ }^{1}$, \\ Anneke C Muller Kobold ${ }^{3}$, Edith J Feskens ${ }^{4}$, André P van Beek', Melanie M van der Klauw ${ }^{1}$ \\ and Bruce HR Wolffenbuttel ${ }^{1 *}$
}

\begin{abstract}
Background: The clustering of metabolic and cardiovascular risk factors is known as metabolic syndrome (MetS). The risk of having MetS is strongly associated with increased adiposity and can be further modified by smoking behavior. Apolipoproteins (apo) associated with low-density lipoprotein-cholesterol (LDL-C) and high-density lipoprotein-cholesterol (HDL-C) may be altered in MetS. This study aimed to examine the association between smoking and the following parameters: MetS and its components, levels of apolipoproteins and estimated lipoprotein particle size, separately for men and women, and in different body mass index (BMI) classes.
\end{abstract}

Methods: We included 24,389 men and 35,078 women aged between 18 and 80 years who participated in the LifeLines Cohort Study between December 2006 and January 2012; 5,685 men and 6,989 women were current smokers. Participants were categorized into three different body mass index (BMI) classes (BMI $<25 ; \mathrm{BMI} 25$ to $30 ; \mathrm{BMI} \geq 30 \mathrm{~kg} / \mathrm{m}^{2}$ ). MetS was defined according to the National Cholesterol Education Program's Adult Treatment Panel III (NCEP:ATPIII) criteria. Blood pressure, anthropometric and lipid measurements were rigorously standardized, and the large sample size enabled a powerful estimate of quantitative changes. The association between smoking and the individual MetS components, and apoA1 and apoB, was tested with linear regression. Logistic regression was used to examine the effect of smoking and daily tobacco smoked on risk of having MetS. All models were age adjusted and stratified by sex and BMI class.

Results: Prevalence of MetS increased with higher BMI levels. A total of $64 \%$ of obese men and $42 \%$ of obese women had MetS. Current smoking was associated with a higher risk of MetS in both sexes and all BMI classes (odds ratio 1.7 to 2.4 for men, 1.8 to 2.3 for women, all $P$ values $<0.001$ ). Current smokers had lower levels of $\mathrm{HDL}$ cholesterol and apoA1, higher levels of triglycerides and apoB, and higher waist circumference than non-smokers (all $P<0.001$ ). Smoking had no consistent association with blood pressure or fasting blood glucose. In all BMI classes, we found a dose-dependent association of daily tobacco consumption with MetS prevalence as well as with lower levels of $\mathrm{HDL}$ cholesterol, higher triglyceride levels and lower ratios of $\mathrm{HDL}$ cholesterol/apoA1 and, only in those with $\mathrm{BMI}<30$, LDL cholesterol/apoB (all $P<0.001$ ).

Conclusions: Smoking is associated with an increased prevalence of MetS, independent of sex and BMI class. This increased risk is mainly related to lower HDL cholesterol, and higher triglycerides and waist circumference. In addition, smoking was associated with unfavorable changes in $a p o A 1$ and $a p o B$, and in lipoprotein particle size. Please see related commentary: http://www.biomedcentral.com/1741-7015/11/196.

Keywords: Metabolic syndrome, Smoking, HDL, Cholesterol, Apolipoproteins, Triglycerides, Obesity, Crosssectional, BMI classes

\footnotetext{
*Correspondence: bwo@umcg.nl

${ }^{\dagger}$ Equal contributors

'Department of Endocrinology, University of Groningen, University Medical

Center Groningen, HPC AA31, PO Box 30001, Groningen 9700 RB,

The Netherlands

Full list of author information is available at the end of the article
}

\section{Biomed Central}

(c) 2013 Slagter et al.; licensee BioMed Central Ltd. This is an Open Access article distributed under the terms of the Creative Commons Attribution License (http://creativecommons.org/licenses/by/2.0), which permits unrestricted use, distribution, and reproduction in any medium, provided the original work is properly cited. 


\section{Background}

Metabolic syndrome (MetS) is a combination of unfavorable health factors including abdominal obesity, dyslipidemia, hypertension and glucose intolerance [1,2] and is strongly associated with increased risk of cardiovascular disease (CVD) and type 2 diabetes [1,2]. One of the key drivers in the development of MetS is obesity [3]. In recent years, the global prevalence of obesity has increased at alarming rates, and MetS and its consequences have become a major public health burden $[4,5]$. This rise in MetS prevalence has also been observed in non-obese individuals [6-8] and there is strong evidence that the increase is mainly the result of unfavorable lifestyle changes, such as inactivity and poor nutrition [9].

Smoking has also been implicated as a risk factor for MetS. Earlier studies have suggested that overall tobacco use is associated with an increased risk of MetS [10,11], most likely due to its effects on waist circumference, blood lipids and blood pressure [10,12,13]. Such metabolic abnormalities may also be modulated by a direct negative effect of smoking on insulin resistance [12]. The degree to which smoking modulates the risk of developing obesity-related MetS still remains unclear, however. While the association between smoking, metabolic disturbances and the presence of MetS has been firmly established in obese individuals $[7,8]$, with a similar trend observed in normal weight individuals [7], these findings could not be confirmed by others $[8,14]$.

Alterations in the size and composition of low-density lipoprotein (LDL) particles and high-density lipoprotein (HDL) particles have been associated with metabolic syndrome [15], and are known to be related to CVD risk [16]. Individuals with altered HDL cholesterol (HDL-C) and triglyceride levels, two components of MetS, are more likely to also have unfavorable changes in the levels of apolipoproteins (apo) A1 and B, the apolipoproteins associated with HDL-C and LDL-C, as well as altered size and composition of these lipoprotein particles [17]. Although small-scale studies have suggested that smoking may influence the levels of apolipoproteins and the composition of lipoproteins [18-20], the extent to which this is associated with prevalent BMI and the risk of MetS is largely unknown. In addition, the latter studies have been published over two decades ago, and since then improved standardization has made apolipoprotein assays more reliable and reproducible [21,22].

The aim of the present study was to examine the association between smoking and the individual components of MetS in normal weight, overweight and obese subjects, in a very large population-based cohort study [23]. We also assessed the relationship between smoking and apolipoprotein levels, and between smoking and lipoprotein particle size, using the HDL-C/apoA1 and LDL-C/apoB ratios as a proxy.

\section{Methods}

\section{Study design and subjects}

The LifeLines Cohort Study is a multidisciplinary prospective population-based cohort study that examines the health and health-related behaviors of participants living in the northeast of The Netherlands [23]. It employs a wide range of procedures to assess the biomedical, sociodemographic, behavioral, physical and psychological factors that contribute to the health and disease of the general population, with a focus on multimorbidity. All participants filled in an extensive questionnaire about health-related items and lifestyle and underwent a clinical examination that included standard anthropometric and blood pressure measurements performed by trained technicians and collection of biological samples. All participants provided written informed consent before participating in the study. The study protocol was approved by the medical ethical review committee of the University Medical Center Groningen.

For this cross-sectional study we included subjects of Western European origin (according to self-reported information in the questionnaire), aged between 18 and 80 years who participated in the LifeLines Cohort Study between December 2006 and January 2012. Individuals who had missing data on BMI $(\mathrm{n}=21)$, or on the variables needed to define MetS $(n=2,044)$, or whose questionnaires were incomplete with regard to smoking behavior $(n=2,202)$ were excluded from analysis. A total of 59,467 individuals were available for the current analysis.

\section{Clinical examination}

The anthropometric measurements height, weight, waist and hip circumference, and blood pressure were conducted by trained technicians using a standardized protocol. Body weight was measured without shoes with $0.1 \mathrm{~kg}$ precision. Height, waist and hip circumference were measured to the nearest $0.5 \mathrm{~cm}$. Waist circumference was measured in standing position with a tape measure all around the body, at the level midway between the lower rib margin and the iliac crest. Systolic and diastolic blood pressures were measured every minute for a period of 10 minutes using an automated Dinamap Monitor (GE Healthcare, Freiburg, Germany). The size of the cuff was chosen according to the arm circumference. The average of the last three readings was recorded for each blood pressure parameter.

\section{Biochemical measurements}

At a second visit, blood was collected in the fasting state, between 8.00 and 10.00 a.m. The blood samples were 
transported under temperature-controlled conditions (at room temperature or at $4^{\circ} \mathrm{C}$, depending on the sample requirements) to the LifeLines central laboratory facility. All measurements were performed the same day. Total and HDL cholesterol were measured using an enzymatic colorimetric method, triglycerides using a colorimetric UV method, and LDL-C using an enzymatic method, all on a Roche Modular P chemistry analyzer (Roche, Basel, Switzerland). Apolipoprotein A1 (apoA1) and apolipoprotein B (apoB) were measured by nephelometry (Siemens, Munich, Germany). Fasting blood glucose was measured using a hexokinase method.

\section{Assessment of metabolic syndrome and lipoprotein particle size}

BMI was calculated as weight $(\mathrm{kg})$ divided by height squared $\left(\mathrm{m}^{2}\right)$. We classified the subjects into three BMI categories: normal weight (BMI $<25.0)$, overweight (BMI 25.0 to 30$)$ or obese (BMI $\geq 30$ ). Individuals with a BMI $<30$ were considered to have MetS if they satisfied at least three of the five criteria named in the revised National Cholesterol Education Program's Adult Treatment Panel III (NCEP:ATPIII, Table 1) [2]. Individuals with a $\mathrm{BMI} \geq 30$ were considered to have MetS if they satisfied at least two of the four MetS criteria (excluding waist circumference since a $\mathrm{BMI} \geq 30$ overrules the waist circumference criterion). The HDL-C/apoA1 ratio and $\mathrm{LDL}-\mathrm{C} / \mathrm{apoB}$ ratio were calculated to estimate differences in $\mathrm{HDL}-\mathrm{C}$ and LDL-C particle size.

\begin{tabular}{|c|c|}
\hline Criteria & Details \\
\hline Raised blood pressure & $\begin{array}{l}\text { Systolic blood pressure (SBP) } \geq 130 \\
\mathrm{mmHg} \text { or diastolic blood pressure (DBP) } \\
\geq 85 \mathrm{mmHg} \text { or use of blood pressure- } \\
\text { lowering medication }\end{array}$ \\
\hline Elevated glucose level & $\begin{array}{l}\text { Fasting blood glucose } \geq 5.6 \mathrm{mmol} / \mathrm{l} \text { or } \\
\text { use of blood glucose-lowering } \\
\text { medication or diagnosis of type } 2 \\
\text { diabetes }\end{array}$ \\
\hline
\end{tabular}

Decreased high-density lipoprotein-cholesterol

Elevated triglycerides
$<1.03 \mathrm{mmol} / \mathrm{l}$ in men or $<1.30 \mathrm{mmol} / \mathrm{l}$ in women or lipid-lowering medical treatment

$\geq 1.70 \mathrm{mmol} / \mathrm{l}$ or medication for elevated triglycerides

Abdominal obesity (increased $\geq 102 \mathrm{~cm}$ in men or $\geq 88 \mathrm{~cm}$ in women waist circumference)

${ }^{a}$ If body mass index (BMI) is $\geq 30 \mathrm{~kg} / \mathrm{m}^{2}$, abdominal obesity can be assumed and waist circumference is not included as a criterion. A person with $\mathrm{BMI} \geq 30$ must satisfy at least two of the four other criteria to be defined as having MetS.

\section{Data description}

Diagnosis of earlier myocardial infarction or hypertension was self-reported, as was the use of medication. Diagnosis of diabetes mellitus was based either on selfreport, or on the finding of a fasting blood glucose $>7$ $\mathrm{mmol} / \mathrm{l}$. Information about smoking was collected from the self-administered questionnaires. Respondents were asked whether they smoked; whether they had smoked during the last month and whether they had ever smoked for an entire year; whether they had stopped smoking; which type of tobacco they currently smoked (cigarette, cigarillo, cigar, pipe tobacco or a mixture of different kinds); and the amount smoked (number of cigarettes smoked per day and/or grams tobacco per week, in the case of pipe smokers). The subjects were classified according to smoking status as non-smoker, former smoker or current smoker. Subjects were defined as a non-smoker if they had not smoked during the last month and had also never smoked for longer than a year. Former smokers were those who had not smoked during the last month but reported to have smoked for longer than a year and had stopped smoking. Current smokers were subjects who reported to have smoked during the last month or those who reported to have smoked for longer than a year and had not stopped smoking. Estimation of current smokers' total tobacco use and their classification into light, moderate and heavy smokers were based on the following quantities: one cigarette $=1 \mathrm{~g}$ tobacco, one cigarillo $=3 \mathrm{~g}$ tobacco and one cigar $=5 \mathrm{~g}$ tobacco. Light smoking was defined as $10 \mathrm{~g} /$ day or less, moderate as 11 to $20 \mathrm{~g} /$ day and heavy as more than $20 \mathrm{~g} /$ day.

\section{Statistical methods}

All analyses were conducted using IBM SPSS Statistics version 20 (IBM Corporation, Armonk, NY, USA). Data are presented as means $\pm \mathrm{SD}$, or geometric mean and interquartile range when they were not normally distributed. For comparisons between groups, analysis of variance was used where appropriate. Linear regression was used to examine the associations between smoking and the five components of MetS as well as between smoking and the apolipoprotein levels and the HDL-C/apoA1 and $\mathrm{LDL}-\mathrm{C} / \mathrm{apoB}$ ratios. Logistic regression was used to examine the effect of smoking and daily tobacco use on the risk of having MetS. This approach generated odds ratios that predicted the odds of having MetS for the different smoking statuses and different amounts of tobacco usage. Since distributions for triglyceride and fasting blood glucose were right skewed, before analysis we log-transformed (natural log) values to approximate normal distribution. All analyses were stratified for sex and BMI class, and were additionally adjusted for age. 
We applied a Bonferroni correction to account for the number of independent tests. A $P$ value of $\leq 0.001$ $(0.05 / 48)$ was regarded as significant, given 48 independent tests (6 statistical models $\times 8$ traits). Since the analyses were performed separately for men and women, and also for each BMI class, we used six models. The eight traits were as follows: (1) systolic and diastolic blood pressure or hypertension; (2) fasting glucose level; (3) HDL-C level; (4) triglyceride level; (5) waist circumference; (6) apoA1 and apoB; (7) HDL-C/ apoA1 and LDL-C/apoB ratios; and (8) MetS.

\section{Results}

The baseline characteristics of the participants are summarized in Table 2. Obesity prevalence was $14.4 \%$ in men and $16.1 \%$ in women. Subjects who were overweight or obese were slightly older than those with normal weight. Among normal weight men, $24.6 \%$ were current smokers, while $22.3 \%$ of the overweight and $23.1 \%$ of the obese were current smokers. Among normal weight women, $21.1 \%$ were current smokers, while $19.6 \%$ of the overweight and $16.8 \%$ of the obese were current smokers. For both sexes, systolic and diastolic blood pressure, serum triglycerides, blood glucose, LDL-C and apoB, as well as the percentage of subjects with type 2 diabetes, showed a consistent increase with increasing BMI. The same trend was observed for the percentage of subjects using medication to control elevated blood pressure, triglycerides or blood glucose. HDL-C and apoA1 levels, as well as the HDL-C/apoA1 ratio, showed a consistent decrease with increasing BMI. While in subjects with BMI $<25$ the overall prevalence of MetS was 3.6\% in men and 2.4\% in women, in the overweight this figure was $21.6 \%$ in men and $16.0 \%$ in women, rising to $64.3 \%$ of obese men and $41.5 \%$ of obese women.

For both sexes, former smokers were older and had higher levels of BMI, blood pressure, LDL-C, total cholesterol, waist circumference and glucose and were more frequently diagnosed with type 2 diabetes than nonsmokers and current smokers (Table 3). Current smokers had the lowest levels of HDL-C and apoA1, the lowest HDL-C/apoA1 ratio, and the highest levels of triglycerides and, in women, apoB.

The percentage of subjects with MetS according to smoking status and daily tobacco consumption are shown in Figure 1. In both men and women, prevalence of MetS was greater in current smokers within each BMI group. In men, smoking was associated with higher MetS prevalence, although in the normal weight and obese men there was no difference between moderate and heavy smokers. In women there was a more pronounced dosage effect, that is, the percentage of individuals with MetS increased with an increase in the amount of tobacco smoked. Former smokers had a higher prevalence of MetS than non-smokers, but it should be taken into account that they were also older.

For all BMI classes and smoking statuses, the percentage of subjects with high blood pressure, elevated blood glucose and elevated triglyceride levels was higher in men than in women, whereas women were more likely than men to have a higher waist circumference (Figure 2). In both sexes, increasing amounts of tobacco smoked were strongly associated with an increase in the number of individuals showing abnormal HDL-C and triglyceride levels. The amount of tobacco smoked was also associated with increased waist circumference, especially in overweight individuals. There were no consistent effects of the amount of tobacco smoked on blood pressure and blood glucose, nor did the amount of tobacco smoked influence blood pressure levels following correction for use of blood pressure-lowering medication.

Table 4 presents the associations between smoking and individual MetS components and between smoking and apolipoprotein levels and ratios, for the three different BMI classes, stratified by sex. There was a significant fall of HDL-C levels associated with greater amount of tobacco smoked in both sexes and all three BMI classes $(P<0.001)$. In addition, the HDL-C/apoA1 ratio was significantly lower for higher amount of tobacco smoked in all BMI classes, and the LDL-C/apoB ratio for the lowest BMI classes $(P<0.001)$. Former smokers had similar HDL-C levels to those of non-smokers. In all BMI classes, there was a consistent positive association between tobacco use and triglyceride levels (all $P$ values $<0.001$ ). In all tobacco use groups, waist circumference was higher than that of non-smokers, independent of sex and BMI class, except for obese male light smokers. In obese female smokers we observed the largest rise in waist circumference: from $2.2 \mathrm{~cm}$ in moderate smokers to $6.4 \mathrm{~cm}$ in heavy smokers (both $P<0.001$ ). Moderate and heavy smoking was not associated with any strong changes in fasting blood glucose level.

The age-corrected odds ratios for having MetS, for men and women separately, in the three BMI classes, are depicted in Figure 3. In all BMI classes there was a significant rise in odds ratio with increasing amount of tobacco smoked. This trend was stronger in women than in men $(P<0.001)$.

\section{Discussion}

In the present study, performed in a large populationbased cohort of almost 60,000 individuals, we investigated the relationship between smoking and the individual components of metabolic syndrome, and the association between smoking and levels of apolipoproteins and estimated lipoprotein particle size. Such a comprehensive and large-scale analysis has not been 
Table 2 Characteristics of the current study population

\begin{tabular}{|c|c|c|c|c|c|c|c|c|}
\hline \multirow[t]{2}{*}{ Characteristic } & \multicolumn{4}{|c|}{$\begin{array}{c}\text { Men } \\
n=24,389(41.0 \%)\end{array}$} & \multicolumn{4}{|c|}{$\begin{array}{c}\text { Women } \\
\mathrm{n}=35,078(59.0 \%)\end{array}$} \\
\hline & BMI <25 & BMI 25 to 30 & $\mathrm{BMI} \geq 30$ & $P$ value & BMI $<25$ & BMI 25 to 30 & $\mathrm{BMI} \geq 30$ & $P$ value \\
\hline n (\%) & $9,112(37.4 \%)$ & $11,763(48.2 \%)$ & $3,514(14.4 \%)$ & & $17,750(50.6 \%)$ & $11,667(33.3 \%)$ & $5,661(16.1 \%)$ & \\
\hline Age, years & $42 \pm 12$ & $47 \pm 11$ & $48 \pm 11$ & $<0.001$ & $42 \pm 12$ & $47 \pm 12$ & $47 \pm 12$ & $<0.001$ \\
\hline $\mathrm{BMI}, \mathrm{kg} / \mathrm{m}^{2}$ & $23.0 \pm 1.5$ & $27.1 \pm 1.4$ & $32.8 \pm 2.9$ & $<0.001$ & $22.4 \pm 1.7$ & $27.1 \pm 1.4$ & $34.1 \pm 3.9$ & $<0.001$ \\
\hline \multicolumn{9}{|l|}{ Smoking status } \\
\hline Non-smoker, n (\%) & 4,467 (49.0\%) & $4,751(40.4 \%)$ & $1,311(37.3 \%)$ & & $8,753(49.3 \%)$ & $5,080(43.5 \%)$ & 2,623 (46.3\%) & \\
\hline Former smoker, n (\%) & 2,401 (26.3\%) & 4,384 (37.3\%) & $1,390(39.6 \%)$ & & $5,248(29.6 \%)$ & 4,298 (36.8\%) & 2,087 (36.9\%) & \\
\hline Current smoker, n (\%) & 2,244 (24.6\%) & 2,628 (22.3\%) & $813(23.1 \%)$ & & $3,749(21.1 \%)$ & 2,289 (19.6\%) & $951(16.8 \%)$ & \\
\hline SBP, mmHg & $127 \pm 12$ & $133 \pm 13$ & $137 \pm 14$ & $<0.001$ & $119 \pm 14$ & $125 \pm 15$ & $130 \pm 15$ & $<0.001$ \\
\hline $\mathrm{DBP}, \mathrm{mmHg}$ & $74 \pm 8$ & $78 \pm 9$ & $80 \pm 9$ & $<0.001$ & $70 \pm 8$ & $73 \pm 9$ & $75 \pm 9$ & $<0.001$ \\
\hline Total cholesterol, mmol/l & $4.9 \pm 1.0$ & $5.2 \pm 1.0$ & $5.2 \pm 1.0$ & $<0.001$ & $4.9 \pm 1.0$ & $5.1 \pm 1.0$ & $5.1 \pm 1.0$ & $<0.001$ \\
\hline LDL-C, mmol/l & $3.17 \pm 0.86$ & $3.47 \pm 0.87$ & $3.44 \pm 0.91$ & $<0.001$ & $2.91 \pm 0.84$ & $3.25 \pm 0.90$ & $3.26 \pm 0.88$ & $<0.001$ \\
\hline $\mathrm{HDL}-\mathrm{C}, \mathrm{mmol} / \mathrm{l}$ & $1.40 \pm 0.32$ & $1.25 \pm 0.29$ & $1.12 \pm 0.26$ & $<0.001$ & $1.69 \pm 0.39$ & $1.54 \pm 0.36$ & $1.38 \pm 0.33$ & $<0.001$ \\
\hline Triglycerides, mmol///a & $0.98(0.71$ to 1.31$)$ & $1.31(0.91$ to 1.80$)$ & $1.62(1.15$ to 2.23$)$ & $<0.001$ & 0.81 (0.61 to 1.04$)$ & 0.99 (0.72 to 1.33$)$ & $1.20(0.86$ to 1.61$)$ & $<0.001$ \\
\hline Apolipoprotein A1, g// ${ }^{\mathrm{b}}$ & $1.47 \pm 0.23$ & $1.41 \pm 0.21$ & $1.36 \pm 0.21$ & $<0.001$ & $1.66 \pm 0.28$ & $1.60 \pm 0.26$ & $1.52 \pm 0.26$ & $<0.001$ \\
\hline HDL-C/apoA1 ratio & $0.93 \pm 0.13$ & $0.86 \pm 0.12$ & $0.81 \pm 0.11$ & $<0.001$ & $1.00 \pm 0.14$ & $0.95 \pm 0.50$ & $0.90 \pm 0.49$ & $<0.001$ \\
\hline Apolipoprotein B, g/lb & $0.91 \pm 0.23$ & $1.01 \pm 0.24$ & $1.05 \pm 0.24$ & $<0.001$ & $0.84 \pm 0.22$ & $0.94 \pm 0.24$ & $0.97 \pm 0.24$ & $<0.001$ \\
\hline LDL-C/apoB ratio ${ }^{b}$ & $3.51 \pm 0.35$ & $3.44 \pm 0.40$ & $3.32 \pm 0.42$ & $<0.001$ & $3.45 \pm 0.36$ & $3.46 \pm 0.36$ & $3.37 \pm 0.38$ & $<0.001$ \\
\hline Blood glucose, $\mathrm{mmol} / \mathrm{I}^{\mathrm{a}}$ & 4.94 (4.60 to 5.20$)$ & $5.18(4.80$ to 5.40$)$ & $5.52(5.00$ to 5.80$)$ & $<0.001$ & $4.70(4.40$ to 4.90$)$ & 4.94 (4.60 to 5.20$)$ & 5.26 (4.80 to 5.50$)$ & $<0.001$ \\
\hline Waist circumference, $\mathrm{cm}$ & $87 \pm 6$ & $98 \pm 6$ & $112 \pm 9$ & $<0.001$ & $79 \pm 7$ & $90 \pm 7$ & $105 \pm 10$ & $<0.001$ \\
\hline BP-lowering medication, n (\%) & $462(5.1 \%)$ & $1,516(12.9 \%)$ & $843(24.0 \%)$ & $<0.001$ & $1,050(5.9 \%)$ & $1,563(13.4 \%)$ & $1,351(23.9 \%)$ & $<0.001$ \\
\hline Statin use, n (\%) & 267 (2.9\%) & $1,008(8.6 \%)$ & $473(13.5 \%)$ & $<0.001$ & $364(2.1 \%)$ & $608(5.2 \%)$ & $457(8.1 \%)$ & $<0.001$ \\
\hline TG-lowering medication, n (\%) & $6(0.1 \%)$ & $32(0.3 \%)$ & $13(0.4 \%)$ & $<0.001$ & $3(0.0 \%)$ & $11(0.1 \%)$ & $8(0.1 \%)$ & 0.0012 \\
\hline Type 2 diabetes, $n$ (\%) & $53(0.6 \%)$ & $203(1.7 \%)$ & $204(5.8 \%)$ & $<0.001$ & $55(0.3 \%)$ & $150(1.3 \%)$ & $267(4.7 \%)$ & $<0.001$ \\
\hline Oral antihyperglycemic medication, $\mathrm{n}(\%)$ & $38(0.4 \%)$ & $175(1.5 \%)$ & $175(5.0 \%)$ & $<0.001$ & $44(0.2 \%)$ & $118(1.0 \%)$ & $211(3.7 \%)$ & $<0.001$ \\
\hline Percentage fulfilling $\geq 3$ out of 5 metabolic syndrome criteria $^{c}$ & $330(3.6 \%)$ & $2,544(21.6 \%)$ & $2,259(64.3 \%)$ & $<0.001$ & $425(2.4 \%)$ & $1,871(16.0 \%)$ & 2,351 (41.5\%) & $<0.001$ \\
\hline
\end{tabular}

Data are presented as mean $\pm \mathrm{SD}$, or median (interquartile range).

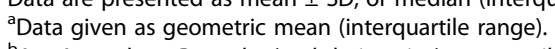

${ }^{\mathrm{b}} \mathrm{ApOA} 1$ and apoB results (and their ratios) were available in 34,613 and 34,601 of the 59,467 subjects, respectively.

'For subjects with $\mathrm{BMI} \geq 30 \mathrm{~kg} / \mathrm{m}^{2}$, two out of four criteria.

Apo apolipoprotein, BMI body mass index, BP blood pressure, DBP diastolic blood pressure, HDL-C high-density lipoprotein-cholesterol, $L D L-C$ low-density lipoprotein-cholesterol, SBP systolic blood pressure, TG triglycerides. 
Table 3 Baseline characteristics of non-smokers, former smokers and current smokers

\begin{tabular}{|c|c|c|c|c|c|c|c|c|}
\hline \multirow[t]{2}{*}{ Smoking status } & \multicolumn{4}{|c|}{ Men } & \multicolumn{4}{|c|}{ Women } \\
\hline & Non-smoker & Former smoker & Current smoker & $P$ value & Non-smoker & Former smoker & Current smoker & $P$ value \\
\hline$n(\%)$ & $10,529(43.2 \%)$ & $8,175(33.5 \%)$ & $5,685(23.3 \%)$ & & $16,456(46.9 \%)$ & $11,633(33.2 \%)$ & $6,989(19.9 \%)$ & \\
\hline Age, years & $42 \pm 11$ & $51 \pm 12$ & $43 \pm 11$ & $<0.001$ & $43 \pm 12$ & $48 \pm 11$ & $42 \pm 11$ & $<0.001$ \\
\hline $\mathrm{BMI}, \mathrm{kg} / \mathrm{m}^{2}$ & $26.1 \pm 3.7$ & $27.0 \pm 3.5$ & $26.2 \pm 3.7$ & $<0.001$ & $25.6 \pm 4.8$ & $26.3 \pm 4.7$ & $25.4 \pm 4.6$ & $<0.001$ \\
\hline $\mathrm{BMI} \geq 30 \mathrm{~kg} / \mathrm{m}^{2}, \mathrm{n}(\%)$ & 1,311 (12.5\%) & 1,390 (17.0\%) & $812(14.3 \%)$ & & 2,623 (15.9\%) & 2,087 (17.9\%) & $951(13.6 \%)$ & \\
\hline $\mathrm{SBP}, \mathrm{mmHg}$ & $130 \pm 13$ & $133 \pm 14$ & $131 \pm 13$ & $<0.001$ & $122 \pm 15$ & $124 \pm 16$ & $121 \pm 14$ & $<0.001$ \\
\hline $\mathrm{DBP}, \mathrm{mmHg}$ & $76 \pm 9$ & $78 \pm 9$ & $76 \pm 9$ & $<0.001$ & $72 \pm 9$ & $73 \pm 9$ & $72 \pm 9$ & $<0.001$ \\
\hline Total cholesterol, mmol// & $5.0 \pm 1.0$ & $5.2 \pm 1.0$ & $5.1 \pm 1.0$ & $<0.001$ & $4.9 \pm 1.0$ & $5.1 \pm 1.0$ & $5.0 \pm 1.0$ & $<0.001$ \\
\hline LDL-C, mmol// & $3.28 \pm 0.86$ & $3.43 \pm 0.89$ & $3.39 \pm 0.92$ & $<0.001$ & $2.99 \pm 0.85$ & $3.18 \pm 0.89$ & $3.14 \pm 0.92$ & $<0.001$ \\
\hline $\mathrm{HDL}-\mathrm{C}, \mathrm{mmol} / \mathrm{l}$ & $1.31 \pm 0.31$ & $1.31 \pm 0.32$ & $1.21 \pm 0.30$ & $<0.001$ & $1.59 \pm 0.38$ & $1.65 \pm 0.40$ & $1.49 \pm 0.38$ & $<0.001$ \\
\hline Triglycerides, mmol// ${ }^{\mathrm{a}}$ & 1.12 (0.78 to 1.54$)$ & 1.25 (0.87 to 1.73$)$ & 1.35 (0.92 to 1.91$)$ & $<0.001$ & 0.87 (0.64 to 1.16$)$ & 0.93 (0.68 to 1.25$)$ & 1.01 (0.73 to 1.36$)$ & $<0.001$ \\
\hline Apolipoprotein A1, g/l & $1.43 \pm 0.22$ & $1.46 \pm 0.22$ & $1.40 \pm 0.22$ & $<0.001$ & $1.61 \pm 0.27$ & $1.66 \pm 0.27$ & $1.57 \pm 0.28$ & $<0.001$ \\
\hline HDL-C/apoA1 ratio & $0.89 \pm 0.13$ & $0.88 \pm 0.13$ & $0.85 \pm 0.13$ & $<0.001$ & $0.97 \pm 0.14$ & $0.98 \pm 0.60$ & $0.92 \pm 0.13$ & $<0.001$ \\
\hline Apolipoprotein B, g/l & $0.94 \pm 0.23$ & $1.00 \pm 0.24$ & $1.00 \pm 0.25$ & $<0.001$ & $0.87 \pm 0.23$ & $0.91 \pm 0.23$ & $0.93 \pm 0.24$ & $<0.001$ \\
\hline LDL-C/apoB ratio & $3.49 \pm 0.37$ & $3.45 \pm 0.41$ & $3.37 \pm 0.40$ & $<0.001$ & $3.44 \pm 0.37$ & $3.47 \pm 0.36$ & $3.38 \pm 0.36$ & $<0.001$ \\
\hline Blood glucose, $\mathrm{mmol} / \mathrm{l}^{\mathrm{a}}$ & 5.05 (4.70 to 5.30$)$ & 5.26 (4.90 to 5.50$)$ & 5.11 (4.70 to 5.40$)$ & $<0.001$ & 4.83 (4.50 to 5.10$)$ & 4.94 (4.60 to 5.20$)$ & $4.84(4.50$ to 5.10$)$ & $<0.001$ \\
\hline Waist circumference, cm & $94 \pm 11$ & $98 \pm 10$ & $95 \pm 11$ & $<0.001$ & $86 \pm 12$ & $89 \pm 12$ & $87 \pm 12$ & $<0.001$ \\
\hline BP-lowering medication, n (\%) & $821(7.8 \%)$ & $1,497(18.3 \%)$ & $503(8.8 \%)$ & $<0.001$ & $1,683(10.2 \%)$ & $1,660(14.3 \%)$ & $621(8.9 \%)$ & $<0.001$ \\
\hline Statin use, n (\%) & $411(3.9 \%$ & $918(11.2 \%$ & 419 (7.4\%) & $<0.001$ & $560(3.4 \%)$ & $594(5.1 \%)$ & 275 (3.9\%) & $<0.001$ \\
\hline TG-lowering medication, n (\%) & $13(0.1 \%)$ & $24(0.3 \%)$ & $14(0.2 \%)$ & NS & $6(0.1 \%)$ & $10(0.1 \%)$ & $6(0.1 \%)$ & NS \\
\hline Type 2 diabetes, n (\%) & $113(1.1 \%)$ & $264(3.2 \%)$ & $83(1.5 \%)$ & $<0.001$ & $188(1.1 \%)$ & $216(1.9 \%)$ & $68(1.0 \%)$ & NS \\
\hline Oral antihyperglycemic medication, n (\%) & $102(1.0 \%)$ & $217(2.7 \%)$ & $69(1.2 \%)$ & $<0.001$ & $154(0.9 \%)$ & $164(1.4 \%)$ & $55(0.8 \%)$ & $<0.001$ \\
\hline
\end{tabular}

Data are presented as mean $\pm \mathrm{SD}$, or median (interquartile range).

${ }^{a}$ Data given as geometric mean (interquartile range).

Apo apolipoprotein, BMI body mass index, BP blood pressure, DBP diastolic blood pressure, HDL-C high-density lipoprotein-cholesterol, LDL-C low-density lipoprotein-cholesterol, NS not significant, SBP systolic blood pressure, $T G$ triglycerides. 


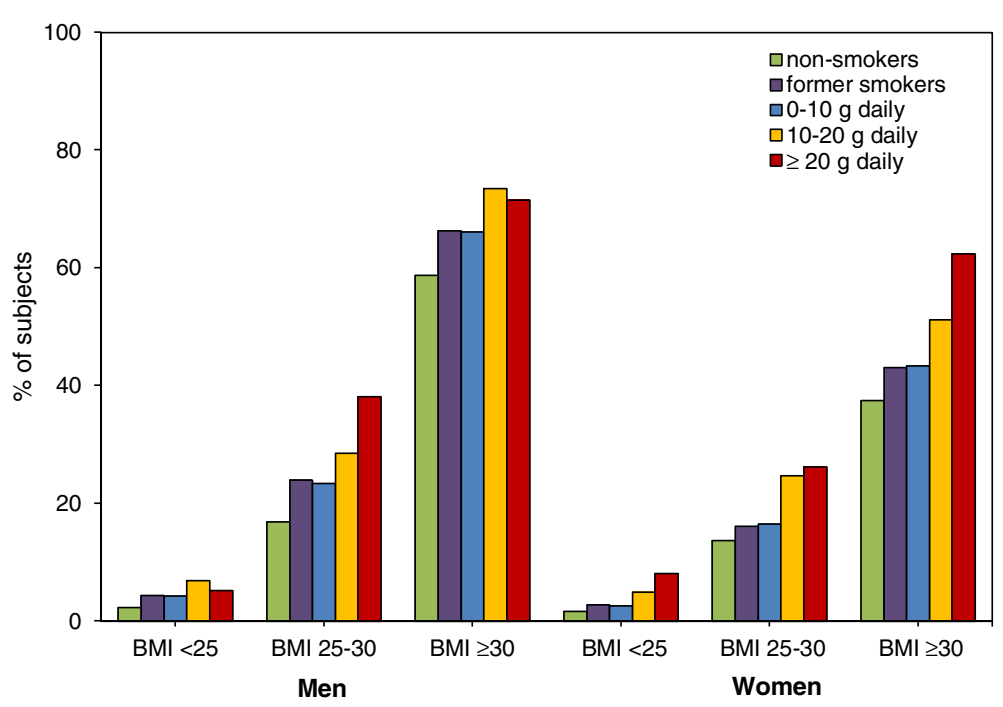

Figure 1 Prevalence of metabolic syndrome in non-smokers, former smokers and current smokers. Note that in all body mass index (BMI) classes prevalence of metabolic syndrome was higher in former smokers than in non-smokers, and that a dose-response relationship was found between prevalence of metabolic syndrome and amount of smoking, especially in women.

performed to date. We demonstrated that in both men and women smoking is associated with a greater prevalence of MetS, irrespective of their BMI. The largest differences between current smokers and non-smokers were observed in the levels of HDL-C and triglycerides, and, to a lesser extent, in waist circumference. While there were no consistent associations between smoking status and either blood pressure or fasting blood glucose levels, there was a dose-dependent relationship between the amount of tobacco smoked and decreased HDL-C levels and increased triglyceride levels. We also found a clear dose-dependent association between the amount of tobacco smoked and reduced ratios of HDL-C/apoA1 and LDL-C/apoB. To our knowledge, we are the first to explore these associations between smoking and levels of apolipoproteins and lipoprotein particle size in such a large cohort of individuals, with rigorously standardized physical and laboratory measurements, while taking into account both sex and BMI levels.

Our analysis revealed that in both men and women the prevalence of MetS was higher in current smokers in each BMI group, than in the non-smokers within that BMI group. Several earlier small-scale studies have reported smoking to be associated with higher prevalence of MetS [24-27]. The positive dose-response relationship between the amount of tobacco smoked and the prevalence of MetS that we observed is also consistent with previous studies $[10,13,26,28]$. However, when BMI was included in our analysis, the odds ratio for having MetS was higher among normal weight smoking subjects than those with higher BMI (Figure 3). This is probably related to the initial lower risk of subjects in this BMI group. Since previous studies have shown an excess of visceral fat to be a major contributor to metabolic abnormalities, overweight and obesity are known to be highly associated with MetS [29], with already a high prevalence of MetS observed in the obese nonsmokers.

With our approach we have been able to calculate precisely the effects of smoking on the lipid parameters. Our data unequivocally show that despite the fact that obese men and women have a lower mean HDL-C than non-obese, the effects of heavy smoking are similar in all three BMI groups, with a consistent 0.10 to $0.14 \mathrm{mmol} / \mathrm{l}$ lower HDL-C for smoking men, and 0.15 to $0.21 \mathrm{mmol} / \mathrm{l}$ lower HDL-C in smoking women, in all three BMI groups (Table 4). The fact that we found current smoking to be mainly associated with lower levels of HDL-C, higher levels of triglycerides and larger waist circumference than the non-smoking status is consistent with earlier cross-sectional studies [28,30]. This observation of a dose-dependent relationship between the daily amount of tobacco smoked and lower HDL-C and higher triglycerides confirms the results of previous reports [13,31-33]. In our study, the magnitude of the effects of tobacco usage on HDL-C varied between 0.04 for light smoking in men, and $0.21 \mathrm{mmol} / \mathrm{l}$ for heavy smoking in normal weight women. The study by Chen et al., comprising 1,164 men, reported a similar dose-response relationship with the largest effect on HDL-C and triglycerides seen in those who smoked more than 40 cigarettes per day [13]. Ishizaka et al. also reported a dose-response association between the number of cigarettes per day and prevalence of MetS in a cohort of 5,033 individuals, 

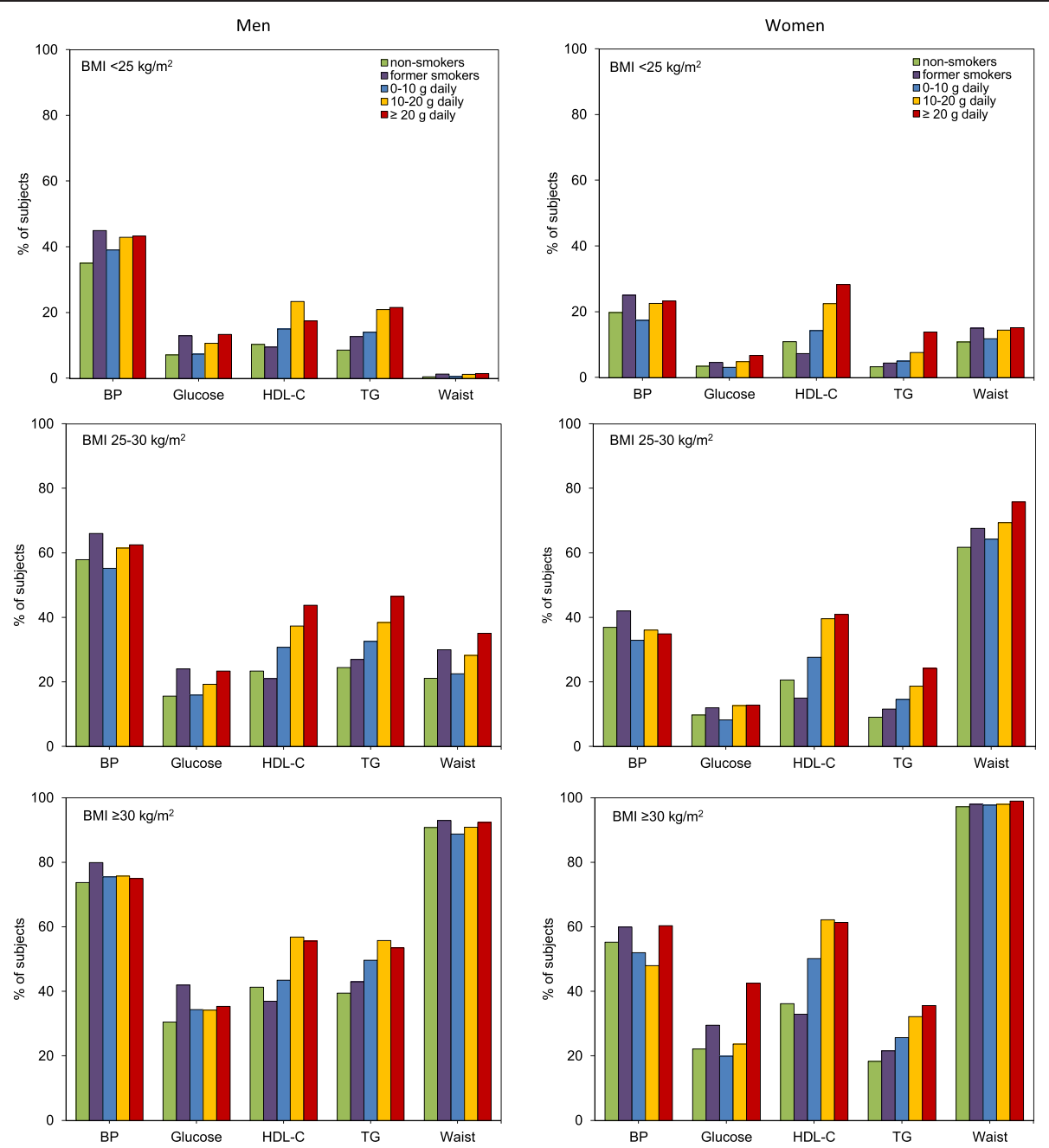

Figure 2 Prevalence of the individual components of metabolic syndrome according to sex (left panel: men; right panel: women) and body mass index (BMI) class. Top: BMl $<25 \mathrm{~kg} / \mathrm{m}^{2}$; middle; BMl 25 to $30 \mathrm{~kg} / \mathrm{m}^{2}$; bottom: BMl $\geq 30 \mathrm{~kg} / \mathrm{m}^{2}$. For all BMl classes, more men met the criteria for high blood pressure, elevated blood glucose and elevated triglyceride levels than did women, while women more frequently met the criteria for high waist circumference. Prevalence of high-density lipoprotein (HDL) abnormalities was not different between men and women. Higher tobacco consumption was particularly associated with abnormalities in $\mathrm{HDL}$ cholesterol and triglycerides, and to a lesser extent with abnormal waist circumference. BP, blood pressure; glucose, blood glucose; HDL-C, high-density lipoprotein-cholesterol; TG, triglycerides; waist, waist circumference.

although they did not examine the influence of the amount of tobacco smoked on the individual MetS components [33]. A recent review summarized the effects of smoking cessation on HDL-C levels: within a few weeks after stopping smoking, HDL-C levels start to increase, resulting in an overall increase of $0.2 \mathrm{mmol} / \mathrm{l}$ [34]. Taken together, these and our data support the causal relationship between smoking and low HDL-C levels.

There are indications that current smoking is associated with increased abdominal obesity [35]. In our study, although current smokers had a greater waist circumference than non-smokers, these differences were rather small. We also observed a consistent increase in the waist circumference with an increase in tobacco smoked in normal weight and overweight men, as well as in normal weight and obese women. Larger effects were especially seen among obese women, where the increase in waist circumference was $2.2 \mathrm{~cm}$ for moderate smokers and $6.4 \mathrm{~cm}$ for heavy smokers. One of the possible mechanisms that might explain these observations is a direct effect of smoking on cortisol production [12,36]. Indeed, it was demonstrated more than three decades ago that smokers have higher fasting plasma cortisol levels than non-smokers $[37,38]$. The increase in cortisol production leads to accumulation of abdominal fat [39], which, in turn, increases waist circumference.

Although some studies have indicated that smoking is related to reduced insulin sensitivity and the development 
Table 4 Effects of daily tobacco smoked on the components of MetS assessed by linear regression

\begin{tabular}{|c|c|c|c|c|c|c|}
\hline \multirow[t]{3}{*}{ Component } & \multicolumn{6}{|c|}{ Current smoking } \\
\hline & \multicolumn{3}{|c|}{ Men } & \multicolumn{3}{|c|}{ Women } \\
\hline & Light & Moderate & Heavy & Light & Moderate & Heavy \\
\hline \multicolumn{7}{|l|}{$\mathrm{SBP}, \mathrm{mmHg}$} \\
\hline \multirow[t]{2}{*}{ BMI $<25$} & 1.24 (0.46 to 2.03$)$ & 1.93 (1.10 to 2.76$)$ & $1.46(-0.25$ to 3.18$)$ & $-0.64(-1.25$ to -0.03$)$ & $0.22(-0.51$ to 0.95$)$ & $-0.01(-1.73$ to 1.71$)$ \\
\hline & NS & $P<0.001$ & NS & NS & NS & NS \\
\hline \multirow[t]{2}{*}{ BMI 25 to 30} & $-0.64(-1.43$ to 0.15$)$ & 1.59 (0.73 to 2.45$)$ & $0.21(-1.30$ to 1.72$)$ & $-1.46(-2.30$ to -0.61$)$ & $-0.06(-1.05$ to 0.92$)$ & $-1.13(-3.37$ to 1.11$)$ \\
\hline & NS & $P<0.001$ & NS & $P=\mathbf{0 . 0 0 1}$ & NS & NS \\
\hline \multirow[t]{2}{*}{$\mathrm{BMI} \geq 30$} & $0.58(-1.08$ to 2.25$)$ & $0.65(-1.02$ to 2.31$)$ & $2.16(-0.24$ to 4.55$)$ & $-0.93(-2.39$ to 0.53$)$ & $-0.74(-2.24$ to 0.77$)$ & $2.04(-0.83$ to 4.91$)$ \\
\hline & NS & NS & NS & NS & NS & NS \\
\hline \multicolumn{7}{|l|}{$\mathrm{DBP}, \mathrm{mmHg}$} \\
\hline \multirow[t]{2}{*}{ BMI $<25$} & $0.44(-0.07$ to 0.95$)$ & 0.94 (0.40 to 1.49$)$ & 1.68 (0.56 to 2.81$)$ & $-0.08(-0.46$ to 0.30$)$ & 0.49 (0.04 to 0.94$)$ & 1.13 (0.06 to 2.19$)$ \\
\hline & NS & $P=\mathbf{0 . 0 0 1}$ & NS & NS & NS & NS \\
\hline \multirow[t]{2}{*}{ BMI 25 to 30} & $-0.38(-0.91$ to 0.15$)$ & 0.66 (0.08 to 1.23$)$ & $0.49(-0.51$ to 1.50$)$ & $-0.27(-0.79$ to 0.25$)$ & 0.56 (0.05 to 1.16$)$ & 0.66 (-0.72 to 2.04$)$ \\
\hline & NS & NS & NS & NS & NS & NS \\
\hline \multirow[t]{2}{*}{$\mathrm{BMI} \geq 30$} & $-0.54(-1.61$ to 0.54$)$ & $0.35(-0.71$ to 1.42$)$ & $0.22(-1.32$ to 1.76$)$ & $-0.24(-1.12$ to 0.65$)$ & $-0.52(-1.44$ to 0.39$)$ & 0.86 (-0.88 to 2.59$)$ \\
\hline & NS & NS & NS & NS & NS & NS \\
\hline \multicolumn{7}{|c|}{$\mathrm{HDL}-\mathrm{C}, \mathrm{mmol} / \mathrm{l}$} \\
\hline \multirow[t]{2}{*}{ BMI $<25$} & $-0.07(-0.09$ to -0.05$)$ & $-0.13(-0.15$ to -0.11$)$ & $-0.14(-0.18$ to -0.09$)$ & $-0.06(-0.08$ to -0.05$)$ & $-0.17(-0.20$ to -0.15$)$ & $-0.21(-0.26$ to -0.16$)$ \\
\hline & $P<0.001$ & $P<0.001$ & $P<0.001$ & $P<0.001$ & $P<0.001$ & $P<0.001$ \\
\hline \multirow[t]{2}{*}{ BMI 25 to 30} & $-0.04(-0.06$ to -0.02$)$ & $-0.10(-0.12$ to -0.08$)$ & $-0.13(-0.16$ to -0.09$)$ & $-0.06(-0.08$ to -0.04$)$ & $-0.17(-0.20$ to -0.15$)$ & $-0.15(-0.20$ to -0.09$)$ \\
\hline & $P<0.001$ & $P<0.001$ & $P<0.001$ & $P<0.001$ & $P<0.001$ & $P<0.001$ \\
\hline \multirow[t]{2}{*}{$\mathrm{BMI} \geq 30$} & $-0.04(-0.07$ to 0.01$)$ & $-0.10(-0.13$ to -0.07$)$ & $-0.10(-0.14$ to -0.06$)$ & $-0.08(-0.12$ to -0.05$)$ & $-0.17(-0.20$ to -0.13$)$ & $-0.20(-0.26$ to -0.14$)$ \\
\hline & NS & $P<0.001$ & $P<0.001$ & $P<0.001$ & $P<0.001$ & $P<0.001$ \\
\hline \multicolumn{7}{|c|}{ Triglycerides, mmol//a } \\
\hline \multirow[t]{2}{*}{ BMI $<25$} & 0.13 (0.10 to 0.15$)$ & $0.26(0.23$ to 0.29$)$ & $0.29(0.22$ to 0.37$)$ & 0.08 (0.06 to 0.09$)$ & 0.18 (0.16 to 0.19$)$ & $0.26(0.21$ to 0.31$)$ \\
\hline & $P<0.001$ & $P<0.001$ & $P<0.001$ & $P<0.001$ & $P<0.001$ & $P<0.001$ \\
\hline \multirow[t]{2}{*}{ BMI 25 to 30} & 0.16 (0.13 to 0.20$)$ & 0.30 (0.25 to 0.34$)$ & 0.40 (0.31 to 0.50$)$ & 0.11 (0.09 to 0.13 ) & 0.21 (0.18 to 0.24$)$ & 0.33 (0.25 to 0.41$)$ \\
\hline & $P<0.001$ & $P<0.001$ & $P<0.001$ & $P<0.001$ & $P<0.001$ & $P<0.001$ \\
\hline \multirow[t]{2}{*}{$\mathrm{BMI} \geq 30$} & 0.14 (0.07 to 0.22 ) & 0.32 (0.22 to 0.41$)$ & 0.35 (0.20 to 0.53$)$ & 0.11 (0.07 to 0.16$)$ & $0.26(0.23$ to 0.31$)$ & 0.33 (0.23 to 0.46$)$ \\
\hline & NS & $P<0.001$ & $P<0.001$ & $P<0.001$ & $P<0.001$ & $P<0.001$ \\
\hline \multicolumn{7}{|c|}{ Blood glucose, $\mathrm{mmol} / \mathrm{l}^{\mathrm{a}}$} \\
\hline \multirow[t]{2}{*}{$\mathrm{BMI}<25$} & 0.02 (0.01 to 0.04 ) & 0.07 (0.04 to 0.10$)$ & 0.13 (0.05 to 0.21$)$ & $-0.01(-0.02$ to 0.01$)$ & 0.05 (0.03 to 0.08 ) & 0.15 (0.08 to 0.24$)$ \\
\hline & NS & $P<0.001$ & NS & NS & NS & $P<0.001$ \\
\hline
\end{tabular}


Table 4 Effects of daily tobacco smoked on the components of MetS assessed by linear regression (Continued)

\begin{tabular}{|c|c|c|c|c|c|c|}
\hline \multirow[t]{2}{*}{ BMI 25 to 30} & $0.01(-0.02$ to 0.03$)$ & 0.07 (0.03 to 0.11$)$ & 0.10 (0.03 to 0.16$)$ & $-0.03(-0.05$ to -0.01$)$ & 0.06 (0.03 to 0.10$)$ & $0.06(-0.01$ to 0.13$)$ \\
\hline & NS & $P=\mathbf{0 . 0 0 1}$ & NS & NS & $P<0.001$ & NS \\
\hline \multirow[t]{2}{*}{$\mathrm{BMI} \geq 30$} & $0.01(-0.06$ to 0.10$)$ & $0.04(-0.05$ to 0.13$)$ & $0.10(-0.05$ to 0.30$)$ & $-0.07(-0.12$ to -0.01$)$ & $0.05(-0.01$ to 0.13$)$ & 0.32 (0.17 to 0.50$)$ \\
\hline & NS & NS & NS & NS & NS & $P<0.001$ \\
\hline \multicolumn{7}{|c|}{ Waist circumference, cm } \\
\hline \multirow[t]{2}{*}{$\mathrm{BMI}<25$} & $0.66(0.27$ to 1.05$)$ & 0.81 (0.39 to 1.23$)$ & $1.20(0.34$ to 2.06$)$ & $0.30(-0.03$ to 0.621$)$ & 0.83 (0.45 to 1.22$)$ & 1.18 (0.26 to 2.09$)$ \\
\hline & $P=\mathbf{0 . 0 0 1}$ & $P<0.001$ & NS & NS & $P<0.001$ & NS \\
\hline \multirow[t]{2}{*}{ BMI 25 to 30} & $0.16(-0.21$ to 0.53$)$ & 1.53 (1.13 to 1.93$)$ & 1.99 (1.28 to 2.69$)$ & $0.74(0.30$ to 1.17$)$ & $1.75(1.24$ to 2.25$)$ & $1.61(0.46$ to 2.76$)$ \\
\hline & NS & $P<0.001$ & $P<0.001$ & $P=\mathbf{0 . 0 0 1}$ & $P<0.001$ & NS \\
\hline \multirow[t]{2}{*}{$\mathrm{BMI} \geq 30$} & $-0.97(-2.05$ to 0.11$)$ & $-0.06(-1.14$ to 1.01$)$ & 2.44 (0.89 to 3.99 ) & $-0.04(-1.10$ to 1.01$)$ & $2.20(1.10$ to 3.29$)$ & $6.44(4.37$ to 8.51$)$ \\
\hline & NS & NS & NS & NS & $P<0.001$ & $P<0.001$ \\
\hline \multicolumn{7}{|l|}{ Apo A1, g/l } \\
\hline \multirow[t]{2}{*}{ BMI $<25$} & $-0.02(-0.04$ to 0.00$)$ & $-0.05(-0.06$ to -0.03$)$ & $-0.04(-0.08$ to -0.00$)$ & $-0.00(-0.02$ to 0.02$)$ & $-0.06(-0.08$ to -0.04$)$ & $-0.07(-0.12$ to -0.02$)$ \\
\hline & NS & $P<0.001$ & NS & NS & $P<0.001$ & NS \\
\hline \multirow[t]{2}{*}{ BMI 25 to 30} & $-0.02(-0.03$ to 0.00$)$ & $-0.03(-0.05$ to -0.01$)$ & $-0.04(-0.07$ to -0.01$)$ & $-0.03(-0.05$ to -0.01$)$ & $-0.07(-0.09$ to -0.04$)$ & $-0.02(-0.07$ to 0.03$)$ \\
\hline & NS & $P<0.001$ & NS & NS & $P<0.001$ & NS \\
\hline \multirow[t]{2}{*}{$\mathrm{BMI} \geq 30$} & $-0.02(-0.05$ to 0.02$)$ & $-0.04(-0.08$ to -0.01$)$ & $-0.03(-0.07$ to -0.02$)$ & $-0.07(-0.10$ to -0.03$)$ & $-0.09(-0.13$ to -0.06$)$ & $-0.09(-0.16$ to -0.03$)$ \\
\hline & NS & NS & NS & $P<0.001$ & $P<0.001$ & NS \\
\hline \multicolumn{7}{|c|}{ HDL-C/apoA1 ratio } \\
\hline \multirow[t]{2}{*}{$\mathrm{BMI}<25$} & $-0.03(-0.04$ to -0.02$)$ & $-0.06(-0.07$ to -0.05$)$ & $-0.06(-0.08$ to -0.03$)$ & $-0.03(-0.04$ to -0.03$)$ & $-0.06(-0.07$ to -0.06$)$ & $-0.09(-0.11$ to -0.06$)$ \\
\hline & $P<0.001$ & $P<0.001$ & $P<0.001$ & $P<0.001$ & $P<0.001$ & $P<0.001$ \\
\hline \multirow[t]{2}{*}{ BMI 25 to 30} & $-0.02(-0.03$ to -0.01$)$ & $-0.05(-0.06$ to -0.04$)$ & $-0.06(-0.08$ to -0.05$)$ & $-0.04(-0.05$ to -0.03$)$ & $-0.06(-0.07$ to -0.05$)$ & $-0.06(-0.09$ to -0.04$)$ \\
\hline & $P<0.001$ & $P<0.001$ & $P<0.001$ & $P<0.001$ & $P<0.001$ & $P<0.001$ \\
\hline \multirow[t]{2}{*}{$\mathrm{BMI} \geq 30$} & $-0.02(-0.03$ to 0.00$)$ & $-0.04(-0.06$ to -0.03$)$ & $-0.06(-0.08$ to -0.03$)$ & $-0.01(-0.03$ to 0.01$)$ & $-0.06(-0.08$ to -0.04$)$ & $-0.06(-0.1$ to -0.03$)$ \\
\hline & NS & $P<0.001$ & $P<0.001$ & NS & $P<0.001$ & $P=<0.001$ \\
\hline \multicolumn{7}{|l|}{ Apo B, g/l } \\
\hline \multirow[t]{2}{*}{$\mathrm{BMI}<25$} & 0.03 (0.01 to 0.05 ) & 0.09 (0.07 to 0.11$)$ & 0.09 (0.05 to 0.13$)$ & 0.03 (0.02 to 0.04$)$ & 0.09 (0.08 to 0.11$)$ & 0.14 (0.11 to 0.18 ) \\
\hline & NS & $P<0.001$ & $P<0.001$ & $P<0.001$ & $P<0.001$ & $P<0.001$ \\
\hline \multirow[t]{2}{*}{ BMI 25 to 30} & 0.03 (0.02 to 0.05$)$ & 0.08 (0.06 to 0.10 ) & 0.09 (0.06 to 0.12 ) & 0.05 (0.03 to 0.06$)$ & 0.08 (0.06 to 0.10$)$ & 0.08 (0.04 to 0.13 ) \\
\hline & $P<0.001$ & $P<0.001$ & $P<0.001$ & $P<0.001$ & $P<0.001$ & $P<0.001$ \\
\hline \multirow[t]{2}{*}{$\mathrm{BMI} \geq 30$} & $0.02(-0.02$ to 0.07$)$ & 0.06 (0.02 to 0.09 ) & 0.07 (0.02 to 0.12 ) & 0.06 (0.03 to 0.09 ) & 0.09 (0.06 to 0.12 ) & 0.12 (0.06 to 0.17 ) \\
\hline & NS & NS & NS & $P<0.001$ & $P<0.001$ & $P<0.001$ \\
\hline
\end{tabular}


Table 4 Effects of daily tobacco smoked on the components of MetS assessed by linear regression (Continued)

\section{LDL-C/apoB ratio}

BMl $<25$

BMI 25 to 30

BMI $\geq 30$

$$
\begin{gathered}
-0.11 \quad(-0.14 \text { to }-0.08) \\
P<0.001
\end{gathered}
$$

$$
-0.08(-0.12 \text { to }-0.06)
$$

$$
P<0.001
$$

$-0.06(-0.12$ to 0.01$)$

$$
\text { NS }
$$

$$
\begin{gathered}
-0.13(-0.16 \text { to }-0.10) \\
P<\mathbf{0 . 0 0 1}
\end{gathered}
$$$$
-0.12(-0.15 \text { to }-0.09)
$$

$$
P<0.001
$$$$
-0.13(-0.20 \text { to }-0.07)
$$

$$
P=<0.001
$$

$$
\begin{gathered}
-0.06(-0.08 \text { to }-0.04) \\
P<0.001
\end{gathered}
$$$$
-0.19(-0.24 \text { to }-0.13)
$$$$
P<0.001
$$

$-0.14(-0.23$ to -0.05$)$
$-0.05(-0.07$ to -0.02$)$

NS

$$
\begin{gathered}
-0.07(-0.10 \text { to }-0.05) \\
P<\mathbf{0 . 0 0 1}
\end{gathered}
$$

$-0.06(-0.09$ to -0.02$)$

$$
P=\mathbf{0 . 0 0 1}
$$

$07(-0.13$ to -0.02$)$
$-0.11(-0.17$ to -0.05$)$

$$
P=\mathbf{0 . 0 0 1}
$$

$-0.13(-0.20$ to -0.06$)$

$$
P<\mathbf{0 . 0 0 1}
$$

-0.08 (-0.18 to 0.02$)$

Data are presented as mean effect size (95\% confidence interval) per unit of component of metabolic syndrome or associated risk factor. Non-smokers within the same BMI class were taken as reference group. See Table 3 for number of subjects per group. Daily tobacco smoked: $\leq 10 \mathrm{~g}$ (light smoker), 11 to $20 \mathrm{~g}$ (moderate smoker), $\geq 20 \mathrm{~g}$ (heavy smoker). $P$ values $\leq 0.001$ are presented in bold.

${ }^{a}$ Data are presented as geometric mean effect size ( $95 \%$ confidence interval) per unit of component of metabolic syndrome.

Apo apolipoprotein, BMI body mass index, BP blood pressure, DBP diastolic blood pressure, HDL-C high-density lipoprotein-cholesterol, LDL-C low-density lipoprotein-cholesterol, NS not significant, SBP systolic blood Apo apolipoprotein, $B M I$
pressure, $T G$ triglycerides. 

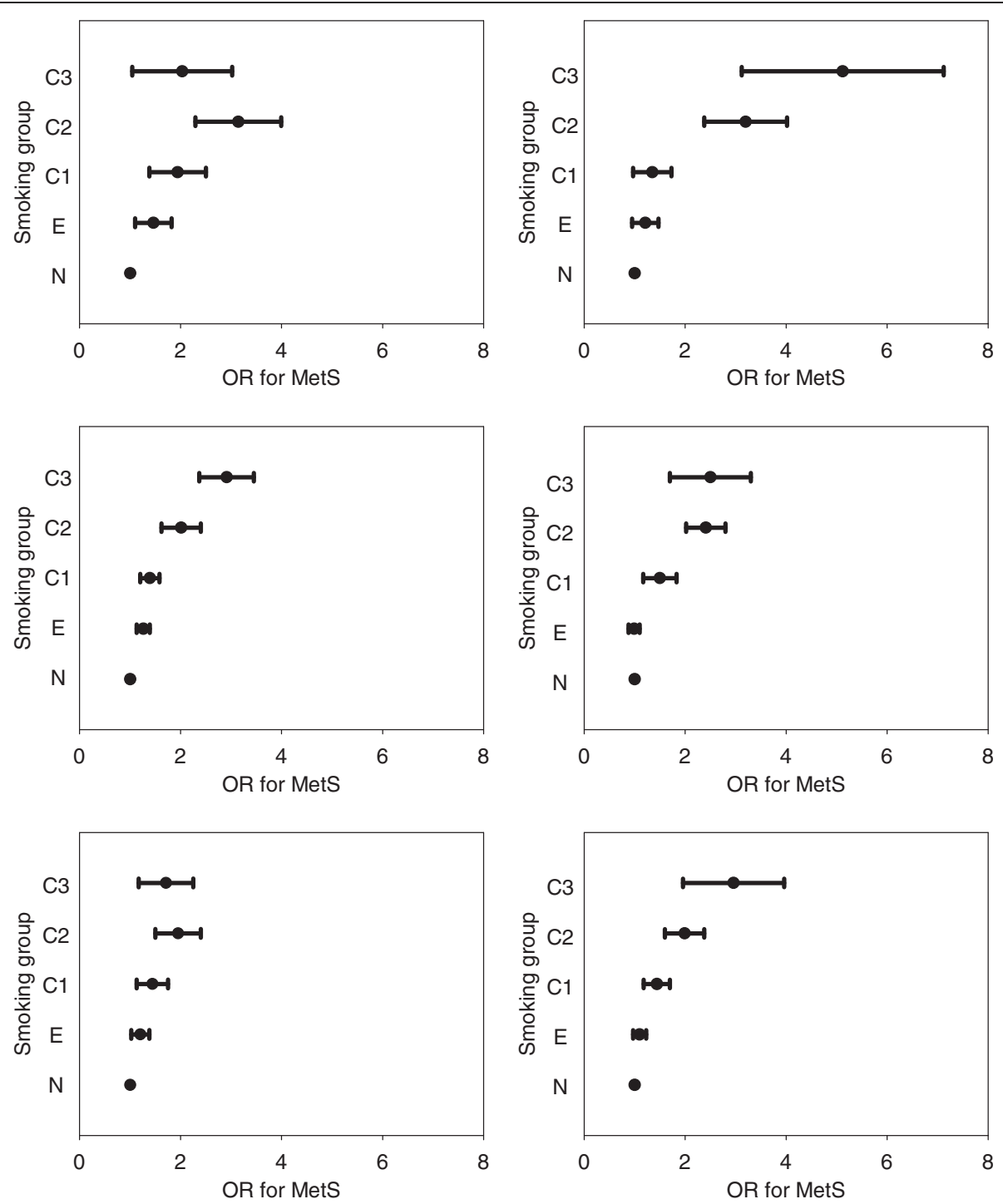

Figure 3 Age-corrected odds ratios for having metabolic syndrome, in men (left panels) and women (right panels) according to body mass index (BMI) class. N, non-smokers; E, former smokers; C1, smokers of 0 to $10 \mathrm{~g}$ tobacco daily; C2, smokers of 10 to $20 \mathrm{~g}$ daily; C3, smokers of $\geq 20$ g daily. Top: BMl <25; middle: BMl 25 to 30; bottom: $\mathrm{BMI} \geq 30 \mathrm{~kg} / \mathrm{m}^{2}$.

of insulin resistance [12,40] and type 2 diabetes [41,42], in our population there was no consistent association between smoking and fasting blood glucose. This confirms the results obtained in other studies [13,30,43]. Ishizaka et al. found a higher prevalence of elevated blood glucose in smoking men, but not in women [33]. Such discrepancy in the results may be due to the different cut-off values for elevated fasting glucose used in the present study (5.6 mmol/l) and that of Ishizaka et al. $(6.1 \mathrm{mmol} / \mathrm{l})$ [33].

While it is well established that acute smoking may cause a rise in blood pressure [44,45], in the chronic situation smokers' blood pressure is similar to or even lower than that of non-smokers [33,44,46], although Primatesta et al. found higher blood pressure in male smokers older than 45 years compared to never smokers
[47]. We found no association between smoking and blood pressure in any of the three BMI classes, even after correction for the use of blood pressure-lowering medication. In addition, we found similar blood pressure in smokers aged 45 and higher versus non-smokers (data not shown). Nevertheless, some studies have suggested that smoking may be a risk factor for developing hypertension [48] or for an increase in blood pressure during exercise [49], although in the latter study smoking cessation did not lead to reduced blood pressure. Weight changes after smoking cessation have been suggested to be involved in this paradox [48].

One of the new findings of our study is the association between smoking and alterations in levels of apolipoproteins and in the size of lipoprotein particles. Until now, 
only a limited number of studies have investigated the relationship between smoking and the levels of apoA1 and apoB, usually involving a small number of participants such as, for example, young adults [18,50], middle-aged men [19,51], or postmenopausal women [20]. In addition, few studies have assessed the effects of smoking on lipoprotein particle size. In the Framingham study, smoking was associated with higher levels of small LDL particles [52]. However, apoA1 and apoB measurement and standardization have considerably improved in the last decade, both because of the appearance of a legal and regulatory framework (the In Vitro Diagnostics (IVD)-directive 98/79/EC and the institution of the Joint Committee on Traceability in Laboratory Medicine (JCTLM)), technical improvements of equipment, and the availability of international reference materials [21]. An additional milestone was the preparation, evaluation and introduction of value-assigned reference materials for monitoring trueness of apolipoprotein test results [22]. ApoA1 is the main protein component of HDL-C particles, and higher levels of apoA1 are associated with lower risk of CVD [53]. We observed that in current smokers plasma apoA1 levels were lower than in non-smokers. In addition, smoking was associated with lower HDL-C/apoA1 ratio, which is a strong indication of smaller HDL particle size. Such alterations of the HDL particle have been negatively associated with heart disease $[54,55]$. While apoA1 is protective, apoB, the main protein component of LDL particles, reflects the atherogenic potential of LDL, and higher levels of apoB are associated with an increased risk of CVD [53]. The fact that we found higher apoB levels and lower LDL$\mathrm{C} / \mathrm{apoB}$ ratios in current smokers than in non-smokers, indicates the presence of increased numbers of small, more dense LDL particles. Such particles have been found to increase the risk not only of atherosclerosis [56,57], but also of coronary artery disease [58] and fatal myocardial infarction [59]. Furthermore, in a 3-year follow-up study among Korean men without MetS, a low LDL-C/apoB ratio was independently associated with development of MetS [60]. Taken together with our findings, the Korean study supports the conclusion that the presence of increased amounts of small, dense LDL particles can be considered both a risk factor for future cardiovascular disease and an early feature of metabolic syndrome.

Our study has several major strengths. Considering the number of participants recruited from the general population $(\mathrm{N}>59,000)$, this is the largest study reporting these results. Our large dataset also enabled to carefully calculate effect sizes, and to perform sufficiently powered subgroup analyses, in subjects of both sexes and in those with normal body weight, overweight, and obesity, which to our knowledge has never been performed before. All participants to the LifeLines Cohort Study have been well characterized, with rigorously standardized blood pressure and anthropometric measurements. In addition, all laboratory measurements of lipids and apolipoproteins have been carried out over a period of 5 years in fresh serum samples, in the same certified laboratory, with the same equipment, and the same rigorous quality assessment and control. This unprecedented sample size also provided us with sufficient statistical power to investigate contradictory associations reported previously.

There are also some limitations to our study. Firstly, since smoking status was based on self-administered questionnaires, we cannot exclude the possibility that misreporting led to some individuals being misclassified with regard to their current smoking status. Considering the large number of participants, we believe that misclassification has only very limited influence on the results obtained, and earlier studies also reported low misclassification rate of smoking status [61]. We should point out that we were unable to identify individuals who had never smoked, nor could we fully take into account the duration of smoking. Secondly, apart from age we could not adjust for other possibly relevant risk factors that influence levels of HDL cholesterol and triglycerides, such as nutrition and alcohol consumption. As data collection for the LifeLines Cohort Study is still ongoing, we hope to be able to investigate the effects of such factors on MetS in the future.

\section{Conclusions}

In this very large study in individuals of western European descent, smoking was associated with an increased risk of MetS. This increased risk was observed in all BMI classes. The elevated risk of having MetS was mainly related to lower HDL cholesterol, higher triglycerides and larger waist circumference. We also found that smoking was associated with unfavorable changes in the levels of apoA1 and apoB and in estimated HDL and LDL particle size, thereby providing a new pathophysiological mechanism linking smoking to increased risk of cardiovascular disease.

\section{Abbreviations}

Apo: Apolipoprotein; BMI: Body mass index; CVD: Cardiovascular disease; HDL: High-density lipoprotein; LDL: Low-density lipoprotein; MetS: Metabolic syndrome; TG: Triglycerides.

\section{Competing interests}

The authors declare that they have no competing interests.

\section{Authors' contributions}

SNS, JVVVO and BHRW carried out the statistical analyses and drafted the manuscript. ACMK coordinated all laboratory measurements and

immunoassays. MMvdK, JMV, EJF and BHRW participated in the design of the cohort study and data collection, while JMV, HMB, SNS and MMvdK carried out the data verification and validation. RPFD and APVB participated in the data interpretation. All authors participated in drafting the manuscript, and read and approved the final version. 


\section{Acknowledgements}

The LifeLines Cohort Study was supported by The Netherlands Organization for Scientific Research (NWO) (grant 175.010.2007.006); the Economic Structure Enhancing Fund (FES) of the Dutch government; the Ministry of Economic Affairs; the Ministry of Education, Culture and Science; the Ministry for Health, Welfare and Sports; the Northern Netherlands Collaboration of Provinces (SNN); the Province of Groningen; University Medical Center Groningen; the University of Groningen; the Dutch Kidney Foundation; and the Dutch Diabetes Research Foundation. This work was supported by the National Consortium for Healthy Ageing, and funds from the European Union's Seventh Framework program (FP7/2007-2013) through the BioSHaRE-EU (Biobank Standardisation and Harmonisation for Research Excellence in the European Union) project, grant agreement 261433. LifeLines (BRIF4568) is engaged in a Bioresource research impact factor (BRIF) policy pilot study, details of which can be found at https://www.bioshare.eu/ content/bioresource-impact-factor. The authors are grateful to the study participants, the staff of the LifeLines Cohort Study and Biobank, and the participating general practitioners and pharmacists. We also thank Dr CM Cobbaert (Leiden University Medical Center) for her comments on apolipoprotein standardization.

\section{Author details}

'Department of Endocrinology, University of Groningen, University Medical Center Groningen, HPC AA31, PO Box 30001, Groningen 9700 RB, The Netherlands. ' ${ }^{2}$ Department of Epidemiology, University of Groningen, University Medical Center Groningen, HPC AA31, PO Box 30001, Groningen 9700 RB, The Netherlands. ${ }^{3}$ Department of Laboratory Medicine, University of Groningen, University Medical Center Groningen, HPC AA31, PO Box 30001, Groningen 9700 RB, The Netherlands. ${ }^{4}$ Division of Human Nutrition, Wageningen University, PO Box 8129, Wageningen $6700 \mathrm{EV}$,

The Netherlands.

Received: 4 May 2013 Accepted: 24 July 2013

Published: 3 September 2013

\section{References}

1. Grundy SM, Cleeman Jl, Daniels SR, Donato KA, Eckel RH, Franklin BA, Gordon DJ, Krauss RM, Savage PJ, Smith SC Jr, Spertus JA, Costa F, American Heart Association, National Heart, Lung, and Blood Institute: Diagnosis and management of the metabolic syndrome: an American Heart Association/National Heart, Lung, and Blood Institute Scientific Statement. Circulation 2005, 112:2735-2752.

2. Alberti KG, Eckel RH, Grundy SM, Zimmet PZ, Cleeman JI, Donato KA Fruchart JC, James WP, Loria CM, Smith SC Jr, International Diabetes Federation Task Force on Epidemiology and Prevention, National Heart, Lung, and Blood Institute, American Heart Association, World Heart Federation, International Atherosclerosis Society, International Association for the Study of Obesity: Harmonizing the metabolic syndrome: a joint interim statement of the International Diabetes Federation Task Force on Epidemiology and Prevention; National Heart, Lung, and Blood Institute; American Heart Association; World Heart Federation; International Atherosclerosis Society; and International Association for the Study of Obesity. Circulation 2009, 120:1640-1645.

3. Primeau V, Coderre L, Karelis AD, Brochu M, Lavoie ME, Messier V, Sladek R, Rabasa-Lhoret R: Characterizing the profile of obese patients who are metabolically healthy. Int J Obes (Lond) 2011, 35:971-981.

4. Batsis JA, Nieto-Martinez RE, Lopez-Jimenez F: Metabolic syndrome: from global epidemiology to individualized medicine. Clin Pharmacol Ther 2007, 82:509-524.

5. Malik VS, Willett WC, Hu FB: Global obesity: trends, risk factors and policy implications. Nat Rev Endocrinol 2013, 9:13-27.

6. Karelis AD, St-Pierre DH, Conus F, Rabasa-Lhoret R, PoehIman ET: Metabolic and body composition factors in subgroups of obesity: what do we know? J Clin Endocrinol Metab 2004, 89:2569-2575.

7. Wildman RP, Muntner P, Reynolds K, McGinn AP, Rajpathak S, Wylie-Rosett J, Sowers MR: The obese without cardiometabolic risk factor clustering and the normal weight with cardiometabolic risk factor clustering: prevalence and correlates of 2 phenotypes among the US population (NHANES 1999-2004). Arch Intern Med 2008, 168:1617-1624
8. Lee K: Metabolically obese but normal weight (MONW) and metabolically healthy but obese $(\mathrm{MHO})$ phenotypes in Koreans: characteristics and health behaviors. Asia Pac J Clin Nutr 2009, 18:280-284.

9. Kemper HC, Post GB, Twisk JW, Van Mechelen W: Lifestyle and obesity in adolescence and young adulthood: results from the Amsterdam Growth And Health Longitudinal Study (AGAHLS). Int I Obes Relat Metab Disord 1999, 23:S34-S40.

10. Nakanishi $\mathrm{N}$, Takatorige T, Suzuki K: Cigarette smoking and the risk of the metabolic syndrome in middle-aged Japanese male office workers. Ind Health 2005, 43:295-301.

11. Sun K, Liu J, Ning G: Active smoking and risk of metabolic syndrome: a meta-analysis of prospective studies. PLoS One 2012, 7:e47791.

12. Chiolero A, Faeh D, Paccaud F, Cornuz J: Consequences of smoking for body weight, body fat distribution, and insulin resistance. Am J Clin Nutr 2008, 87:801-809

13. Chen CC, Li TC, Chang PC, Liu CS, Lin WY, Wu MT, Li Cl, Lai MM, Lin CC: Association among cigarette smoking, metabolic syndrome, and its individual components: the metabolic syndrome study in Taiwan. Metabolism 2008, 57:544-548.

14. Velho S, Paccaud F, Waeber G, Vollenweider P, Marques-Vidal P: Metabolically healthy obesity: different prevalences using different criteria. Eur J Clin Nutr 2010, 64:1043-1051.

15. Garin MC, Kalix B, Morabia A, James RW: Small, dense lipoprotein particles and reduced paraoxonase-1 in patients with the metabolic syndrome. J Clin Endocrinol Metab 2005, 90:2264-2269.

16. Siri PW, Krauss RM: Influence of dietary carbohydrate and fat on LDL and HDL particle distributions. Curr Atheroscler Rep 2005, 7:455-459.

17. Carmena R, Duriez P, Fruchart JC: Atherogenic lipoprotein particles in atherosclerosis. Circulation 2004, 109:||I2-III7.

18. Donahue RP, Orchard TJ, Stein EA, Kuller LH: Apolipoproteins Al, All and B in young adults: associations with CHD risk factors. The Beaver County experience. J Chronic Dis 1986, 39:823-830.

19. Periti M, Salvaggio A, Quaglia G, Di ML, Miano L: Effect of cigarette smoking and coffee consumption on apolipoprotein B levels. Eur J Epidemiol 1990, 6:76-79.

20. Haarbo J, Hassager C, Schlemmer A, Christiansen C: Influence of smoking, body fat distribution, and alcohol consumption on serum lipids, lipoproteins, and apolipoproteins in early postmenopausal women. Atherosclerosis 1990, 84:239-244.

21. Marcovina SM, Albers JJ, Kennedy H, Mei JV, Henderson LO, Hannon WH International Federation of Clinical Chemistry standardization project for measurements of apolipoproteins A-I and B. IV: Comparability of apolipoprotein B values by use of International Reference Material. Clin Chem 1994, 40:586-592.

22. Cobbaert C, Weykamp C, Baadenhuijsen H, Kuypers A, Lindemans J, Jansen R: Selection, preparation, and characterization of commutable frozen human serum pools as potential secondary reference materials for lipid and apolipoprotein measurements: study within the framework of the Dutch project "Calibration 2000". Clin Chem 2002, 48:1526-1538.

23. Stolk RP, Rosmalen JG, Postma DS, de Boer RA, Navis G, Slaets JP, Ormel J, Wolffenbuttel BH: Universal risk factors for multifactorial diseases: LifeLines: a three-generation population-based study. Eur J Epidemiol 2008, 23:67-74.

24. Geslain-Biquez C, Vol S, Tichet J, Caradec A, D'Hour A, Balkau B: The metabolic syndrome in smokers. The D.E.S.I.R. study. Diabetes Metab 2003, 29:226-234

25. Zhu S, St-Onge MP, Heshka S, Heymsfield SB: Lifestyle behaviors associated with lower risk of having the metabolic syndrome. Metabolism 2004, 53:1503-1511.

26. Weitzman M, Cook S, Auinger P, Florin TA, Daniels S, Nguyen M, Winickoff JP: Tobacco smoke exposure is associated with the metabolic syndrome in adolescents. Circulation 2005, 112:862-869.

27. Wilsgaard T, Jacobsen BK: Lifestyle factors and incident metabolic syndrome. The Tromso Study 1979-2001. Diabetes Res Clin Pract 2007, 78:217-224.

28. Nakashita Y, Nakamura M, Kitamura A, Kiyama M, Ishikawa Y, Mikami H: Relationships of cigarette smoking and alcohol consumption to metabolic syndrome in Japanese men. J Epidemiol 2010, 20:391-397.

29. Despres JP: Is visceral obesity the cause of the metabolic syndrome? Ann Med 2006, 38:52-63. 
30. Berlin I, Lin S, Lima JA, Bertoni AG: Smoking status and metabolic syndrome in the multi-ethnic study of atherosclerosis. A cross-sectional study. Tob Induc Dis 2012, 10:9

31. Facchini FS, Hollenbeck CB, Jeppesen J, Chen YD, Reaven GM: Insulin resistance and cigarette smoking. Lancet 1992, 339:1128-1130.

32. Oh SW, Yoon YS, Lee ES, Kim WK, Park C, Lee S, Jeong EK, Yoo T, Korea National Health and Nutrition Examination Survey: Association between cigarette smoking and metabolic syndrome: the Korea national health and nutrition examination survey. Diabetes Care 2005, 28:2064-2066.

33. Ishizaka $N$, Ishizaka $Y$, Toda $E$, Nagai $R$, Yamakado M: Association between cigarette smoking, white blood cell count, and metabolic syndrome as defined by the Japanese criteria. Intern Med 2007, 46:1167-1170.

34. Chelland CS, Moffatt RJ, Stamford BA: Smoking and smoking cessation the relationship between cardiovascular disease and lipoprotein metabolism: a review. Atherosclerosis 2008, 201:225-235.

35. Saarni SE, Pietilainen K, Kantonen S, Rissanen A, Kaprio J: Association of smoking in adolescence with abdominal obesity in adulthood: a followup study of 5 birth cohorts of Finnish twins. Am J Public Health 2009, 99:348-354.

36. Chiodera P, Volpi R, Capretti L, Speroni G, Necchi-Ghiri S, Caffarri G, Colla R, Coiro V: Abnormal effect of cigarette smoking on pituitary hormone secretions in insulin-dependent diabetes mellitus. Clin Endocrinol (Oxf) 1997, 46:351-357.

37. Cryer PE, Haymond MW, Santiago JV, Shah SD: Norepinephrine and epinephrine release and adrenergic mediation of smoking-associated hemodynamic and metabolic events. N Engl J Med 1976, 295:573-577.

38. Friedman AJ, Ravnikar VA, Barbieri RL: Serum steroid hormone profiles in postmenopausal smokers and nonsmokers. Fertil Steril 1987, 47:398-401.

39. Pasquali R, Vicennati V: Activity of the hypothalamic-pituitary-adrenal axis in different obesity phenotypes. Int J Obes Relat Metab Disord 2000, 24:S47-S49.

40. Houston TK, Person SD, Pletcher MJ, Liu K, Iribarren C, Kiefe Cl: Active and passive smoking and development of glucose intolerance among young adults in a prospective cohort: CARDIA study. BMJ 2006, 332:1064-1069.

41. Hu FB, Manson JE, Stampfer MJ, Colditz G, Liu S, Solomon CG, Willett WC: Diet, lifestyle, and the risk of type 2 diabetes mellitus in women. $N$ Engl J Med 2001, 345:790-797.

42. Foy CG, Bell RA, Farmer DF, Goff DC Jr, Wagenknecht LE: Smoking and incidence of diabetes among U.S. adults: findings from the Insulin Resistance Atherosclerosis Study. Diabetes Care 2005, 28:2501-2507.

43. Hughes K, Choo M, Kuperan P, Ong CN, Aw TC: Cardiovascular risk factors in relation to cigarette smoking: a population-based survey among Asians in Singapore. Atherosclerosis 1998, 137:253-258.

44. Green MS, Jucha E, Luz Y: Blood pressure in smokers and nonsmokers: epidemiologic findings. Am Heart J 1986, 111:932-940.

45. Barutcu I, Esen AM, Degirmenci B, Acar M, Kaya D, Turkmen M, Melek M, Onrat E, Esen OB, Kirma C: Acute cigarette smoking-induced hemodynamic alterations in the common carotid arter-a transcranial Doppler study-. Circ J 2004, 68:1127-1131.

46. Leone A: Smoking and hypertension: independent or additive effects to determining vascular damage? Curr Vasc Pharmacol 2011, 9:585-593.

47. Primatesta P, Falaschetti E, Gupta S, Marmot MG, Poulter NR: Association between smoking and blood pressure: evidence from the health survey for England. Hypertension 2001, 37:187-193.

48. Niskanen L, Laaksonen DE, Nyyssönen K, Punnonen K, Valkonen VP, Fuentes R, Tuomainen TP, Salonen R, Salonen JT: Inflammation, abdominal obesity, and smoking as predictors of hypertension. Hypertension 2004, 44:859-865.

49. Mundal R, Kjeldsen SE, Sandvik L, Erikssen G, Thaulow E, Erikssen J: Predictors of 7-year changes in exercise blood pressure: effects of smoking, physical fitness and pulmonary function. J Hypertens 1997, 15:245-249.

50. Chu NF, Ding YA, Wang DJ, Shieh SM: Relationship between smoking status and cardiovascular disease risk factors in young adult males in Taiwan. J Cardiovasc Risk 1996, 3:205-208.

51. Cuesta C, Sánchez-Muniz FJ, García-La Cuesta A, Garrido R, Castro A, San-Felix B, Domingo A: Effects of age and cigarette smoking on serum concentrations of lipids and apolipoproteins in a male military population. Atherosclerosis 1989, 80:33-39.
52. Shearman AM, Demissie S, Cupples LA, Peter I, Schmid CH, Ordovas JM, Mendelsohn ME, Housman DE: Tobacco smoking, estrogen receptor alpha gene variation and small low density lipoprotein level. Hum Mol Genet 2005, 14:2405-2413.

53. Walldius G, Jungner I: Apolipoprotein B and apolipoprotein A-l: risk indicators of coronary heart disease and targets for lipid-modifying therapy. J Intern Med 2004, 255:188-205.

54. Arsenault BJ, Lemieux I, Després JP, Gagnon P, Wareham NJ, Stroes ES, Kastelein JJ, Khaw KT, Boekholdt SM: HDL particle size and the risk of coronary heart disease in apparently healthy men and women: the EPIC-Norfolk prospective population study. Atherosclerosis 2009, 206:276-281.

55. Parish $S$, Peto R, Palmer A, Clarke R, Lewington S, Offer A, Whitlock G, Clark S, Youngman L, Sleight P, Collins R, International Studies of Infarct Survival Collaborators: The joint effects of apolipoprotein B, apolipoprotein A1, LDL cholesterol, and HDL cholesterol on risk: 3510 cases of acute myocardial infarction and 9805 controls. Eur Heart J 2009, 30:2137-2146.

56. Berneis KK, Krauss RM: Metabolic origins and clinical significance of LDL heterogeneity. J Lipid Res 2002, 43:1363-1379.

57. Sacks FM, Campos H: Clinical review 163: Cardiovascular endocrinology: low-density lipoprotein size and cardiovascular disease: a reappraisal. J Clin Endocrinol Metab 2003, 88:4525-4532.

58. El Harchaoui K, van der Steeg WA, Stroes ES, Kuivenhoven JA, Otvos JD, Wareham NJ, Hutten BA, Kastelein JJ, Khaw KT, Boekholdt SM: Value of low-density lipoprotein particle number and size as predictors of coronary artery disease in apparently healthy men and women: the EPIC-Norfolk Prospective Population Study. J Am Coll Cardiol 2007, 49:547-553

59. Jungner I, Sniderman AD, Furberg C, Aastveit AH, Holme I, Walldius G: Does low-density lipoprotein size add to atherogenic particle number in predicting the risk of fatal myocardial infarction? Am J Cardiol 2006, 97:943-946.

60. Kwon CH, Kim BJ, Kim BS, Kang JH: Low-density lipoprotein cholesterol to apolipoprotein $B$ ratio is independently associated with metabolic syndrome in Korean men. Metabolism 2011, 60:1136-1141.

61. Noonan D, Jiang $Y$, Duffy SA: Utility of biochemical verification of tobacco cessation in the Department of Veterans Affairs. Addict Behav 2013, 38:1792-1795.

doi:10.1186/1741-7015-11-195

Cite this article as: Slagter et al:: Associations between smoking, components of metabolic syndrome and lipoprotein particle size. BMC Medicine 2013 11:195.

\section{Submit your next manuscript to BioMed Central and take full advantage of:}

- Convenient online submission

- Thorough peer review

- No space constraints or color figure charges

- Immediate publication on acceptance

- Inclusion in PubMed, CAS, Scopus and Google Scholar

- Research which is freely available for redistribution 